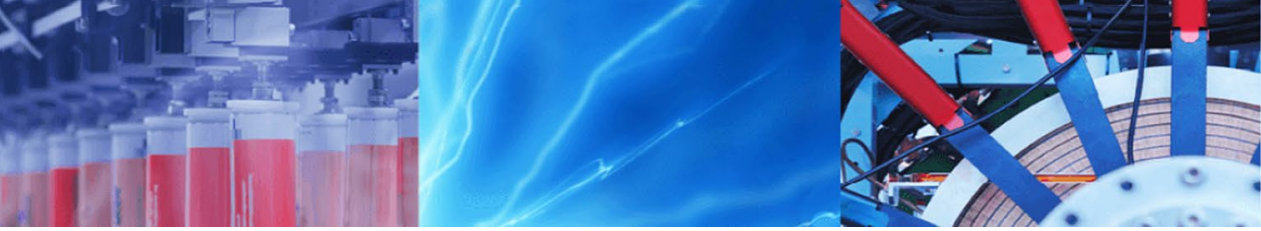

Research Article

\title{
Acoustic emission characteristics of unidirectional glass/epoxy composites under mixed-mode fracture
}

\author{
Stergios Goutianos ${ }^{1}$ (D) \\ () Springer Nature Switzerland AG 2019
}

\begin{abstract}
Delamination is one of the most critical failure modes of composite materials and structures. An approach to avoid conservative designs is to use more damage tolerant composite materials. For this approach to be successful, a reliable structural health monitoring system is required to detect and identify damage during operation. In this paper, the link between mode mixity and acoustic emission characteristics is investigated. While there is a large body of research on analysis of acoustic emission for different materials and loading cases, the current work is focused on simple acoustic emission features and examine their dependence on a wide range of mode mixities. It is shown that there is a strong dependence of the acoustic emission characteristics on the mode mixity and in particular between mode I dominated and mode II dominated fracture. The results obtained could be used to develop tools to identify the type of delamination in composite structures during operation.
\end{abstract}

Keywords Fracture energy $\cdot$ Acoustic emission $\cdot$ DCB $\cdot$ Mix mode fracture $\cdot$ Composites

\section{Introduction}

The requirement of stiff and lightweight structures in various applications such as wind energy, aerospace and marine leads to an increased use of composite materials (fibre reinforced plastics). Composite structures, however, contain both defects and imperfections from the manufacturing processes and damage that occurs due to usage or damage that develops during usage $[1,2]$. The use of a conservative approach with sufficiently large safety factors allows the design of composite structures with explicitly addressing the defects and damage. Such a design philosophy, however, leads to structures that are far from optimum. To obtain cost-effective light-weight structures, the concept of damage tolerance was introduced in the 70s in the aerospace sector $[3,4]$. It ensures that a structure can sustain certain level of damage that can be detected and repaired though regular inspection intervals [2].
The deterministic design approach with safety factors it can also result in unsafe designs (opposite to conservative design) due to inherent uncertainties of the composite structure at all composite levels [5]. More advanced probabilistic design approaches, therefore, have been developed taking into account the scatter in the composite structural response $[5,6]$. Optimal structural reliability can be determined by cost-benefit analysis $[7,8]$. Although, probabilistic design can predict the risk of failure of a structure in average (in a group of structures), it cannot predict the risk of failure of a specific structure [9].

A different design approach, termed condition monitoring and maintenance, was recently proposed by McGugan et al. [9]. It combines the use of damage tolerant composite materials and a structural health monitoring system to detect in-service damage in every individual structure. Knowing the extend of damage and damage type, models can be used to estimate the severity of damage and decide if a repair is necessary or the particular structure

Stergios Goutianos, gout@dtu.dk | 'Department of Wind Energy, Section of Composite Mechanics and Structures, Technical University of Denmark, Risø Campus, 4000 Roskilde, Denmark.

SN Applied Sciences (2019) 1:474 | https://doi.org/10.1007/s42452-019-0499-z

Received: 15 February 2019 / Accepted: 13 April 2019 / Published online: 20 April 2019

SN Applied Sciences

A SPRINGER NATURE journal 
can continue to safely operate. This approach requires a reliable structural health monitoring system to detect and characterise the damage in a structure.

Several methods have been developed to in-situ identify the damage state in a composite. Electrical resistance measurements can detect damage in conductive composites such as carbon fibre reinforced polymers $[10,11]$ but not in glass fibre reinforced composites. Embedded Fibre Bragg gratings (FBGs), which measure changes in internal strain [12], can be used to detect damage events. FBGs have been successfully used to study delamination of composites under static and fatigue loading $[13,14]$. Embedding however a number of a FBGs in large structure may lead to significant manufacturing issues in particular when vacuum infusion is used. Instead of embedded sensing methods, surface sensing techniques may be easier to apply in practice. Acoustic Emission (AE), measuring stress waves with piezoelectric transducers, is a relatively easy method with respect to both monitoring and recording signals. Analysis and interpretation, however, of the $A E$ data is still a challenge [15].

As mentioned above, the condition monitoring and maintenance approach is based on the use of damage tolerant materials. Composite materials can fail along weak planes by failure modes that create a large fibre bridging zone [16]. Fibre bridging can significantly increase the fracture resistance [17] and therefore increase the damage tolerance. Unlike isotropic materials where the crack tends to follow a mode I path, in composite materials the crack can propagate along weak interfaces and thus fracture can be mixed mode $[18,19]$. Figure 1 a shows a schematic illustration of Double Cantilever Specimen (DCB) under arbitrary mixed mode loading (uneven pure bending moments) with a large fracture process zone.

The fracture process zone is divided in a crack tip fracture process zone and a crack wake zone (or bridging zone) as shown in Fig. 1b. Usually, the size of the crack tip fracture process zone is much smaller than any dimension of the specimen (or structure). On the other hand, the size of the bridging zone is often comparable or even larger than some dimensions of a specimen (or structure). It is the fibre bridging zone that increases the damage tolerance of composite materials.

The purpose of the present study is to investigate the Acoustic Emission (AE) characteristics of a unidirectional composite material exhibiting large scale fracture process zone under mixed mode fracture. It is examined if the $A E$ characteristics depend on the mode mixity and on the extend of the fracture process zone as it involves under increasingly applied load. It is envisioned that based on such knowledge, the type and damage size could be determined in a larger structure which is the prerequisite for the condition monitoring and maintenance approach.

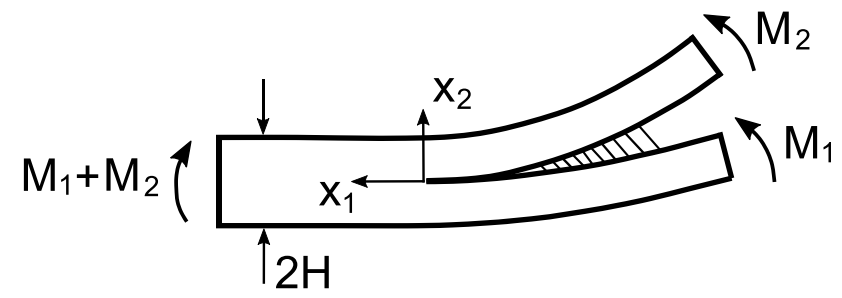

(a)

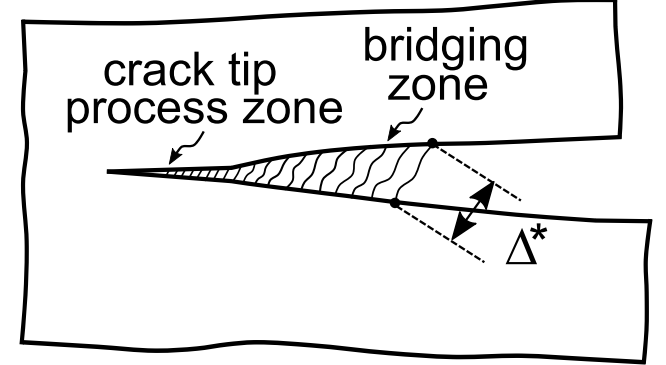

(b)

Fig. 1 Schematic illustration a of a DCB specimen under mixed mode loading and $\mathbf{b}$ for the fracture process zone composed of $\mathbf{a}$ crack tip fracture process zone and a bridging zone

A unidirectional glass/epoxy composite material, typical in wind turbine blades, is used for this purpose.

\section{Experimental procedure}

\subsection{Specimen manufacturing}

A laminate was manufactured by vacuum infusion of an epoxy resin into layers of nearly unidirectional E-glass fabrics obtained from Saertex. The fabric consisted of $0^{\circ}$ bundles of 2400 tex and an area weight of $1134 \mathrm{~g} / \mathrm{m}^{2}$. The fibre diameter was $17 \mu \mathrm{m}$. The area weight of the $90^{\circ}$ bundles (support threads), with a tex value equal to 68, was $1134 \mathrm{~g} /$ $\mathrm{m}^{2}$. The diameter of the fibres was $10 \mu \mathrm{m}$. The fibre bundles were stitched together using a polyester (110 dtex and $12 \mathrm{~g} / \mathrm{m}^{2}$ ) tricot-warp stitching. The epoxy matrix material, Araldite LY 1568, and the hardener, Aradur 3489 CH, were provided by Huntsman.

The fabrics were placed with the $90^{\circ}$ bundles facing down. A $35 \pm 15 \mu \mathrm{m}$ thick and $60 \mathrm{~mm}$ wide perforated release film was placed in the middle of the fabrics along one of the edges of the laminate. The perforated release film (slip foil) acted as crack starter and ensured good infusion quality. Then, the epoxy resin was infused. The curing cycle was $19 \mathrm{~h}$ at $40^{\circ} \mathrm{C}$ followed by $5 \mathrm{~h}$ at $75^{\circ} \mathrm{C}$. The Young's modulus in the fibre direction, $E_{11}$, was equal to $38 \mathrm{GPa}$.

The test specimens (beams) were subsequently cut from the laminate. The specimen length, $L$, was $500 \mathrm{~mm}$, 
the width, $B$, was $30 \mathrm{~mm}$ and the height $2 H$ was $14 \mathrm{~mm}$ (Fig. 2). Steel parts, to allow mounting of the specimens to the test fixture, were fitted to the composite beams by screws and glue. Pins were placed in the neutral axis of each beam at the end of the slip foil (see Fig. 2). The pins were used to mount an extensometer to measure the distance between the pins, $\Delta^{*}$, under loading, which is approximately equal to the end-opening of the fracture process zone.

\subsection{Test procedure}

The tests were performed using a test fixture which applies pure uneven bending moments $\left(M_{1}\right.$ and $\left.M_{2}\right)$ via two transverse arms as shown in Fig. 2a [20]. The moment ratio $M_{1} / M_{2}$ was controlled by adjusting the length of the transverse (moment) arms since $M_{1}=P \ell_{1}$ and $M_{2}=P \ell_{2}$. The force, $P$, was measured by two load cells and the average value was used to calculate the applied moments. The experiments were conducted at constant displacement rate of the lower beam (see Fig. 2a). The data from the load cells and extensometer were recorded with a frequency of $25 \mathrm{~Hz}$.

To calculate the fracture energy, $J_{R}$, the path independent $J$ integral [21] is used. The $J$ integral along the external boundaries of the DCB specimen and under plane strain conditions is given by [20]:
$J_{\text {ext }}=\left(1-v_{12}^{2}\right) \frac{21\left(M_{1}^{2}+M_{2}^{2}\right)-6 M_{1} M_{2}}{4 B^{2} H^{3} E_{11}}$, for $\left|M_{1}\right|<M_{2}$

where $M_{1}$ and $M_{2}$ are measured during the experiment and $v_{12}$ is the Poisson's ratio with an assumed value equal to 0.3 . Equation 1 is valid for both small (Linear Elastic Fracture Mechanics, LEFM) and large scale fracture problems. Under LEFM, the mode mixity is [22]:

$\psi=\tan ^{-1}\left\{\frac{\sqrt{3}}{2}\left(\frac{1+M_{1} / M_{2}}{1-M_{1} / M_{2}}\right)\right\}$

The LEFM definition of the mode mixity will be used in the present study although the problem investigated is a large scale fracture problem. For this reason, the $M_{1} / M_{2}$ ratio will be also given together with $\psi$.

The experiments were recorded with a video camera (50 fps) to observe the development of the fracture process zone under loading. The video recording was also used to measure the end-opening, $\Delta^{*}$, e.g. the opening at the end of the fracture process zone. Thus, the end-opening was measured both with the extensometer and the video recording. $\Delta^{*}$ was measured from the video recording using the digital image correlation software Gom Correlate. From the relative movement of two points, one on each beam of the DCB specimens,
Fig. 2 Schematic illustration of the a test fixture using a wire and rollers to apply pure uneven bending moments. As the lower beam moves in the $x_{1}$ direction, the force in the wire increases, and $\mathbf{b}$ of the DCB specimen and position of the AE sensors. $L=500$ $\mathrm{mm}, 2 H=14 \mathrm{~mm}, B=30 \mathrm{~mm}$, $a=60 \mathrm{~mm}, d_{1}=10 \mathrm{~mm}$ and $d_{2}=260 \mathrm{~mm}$

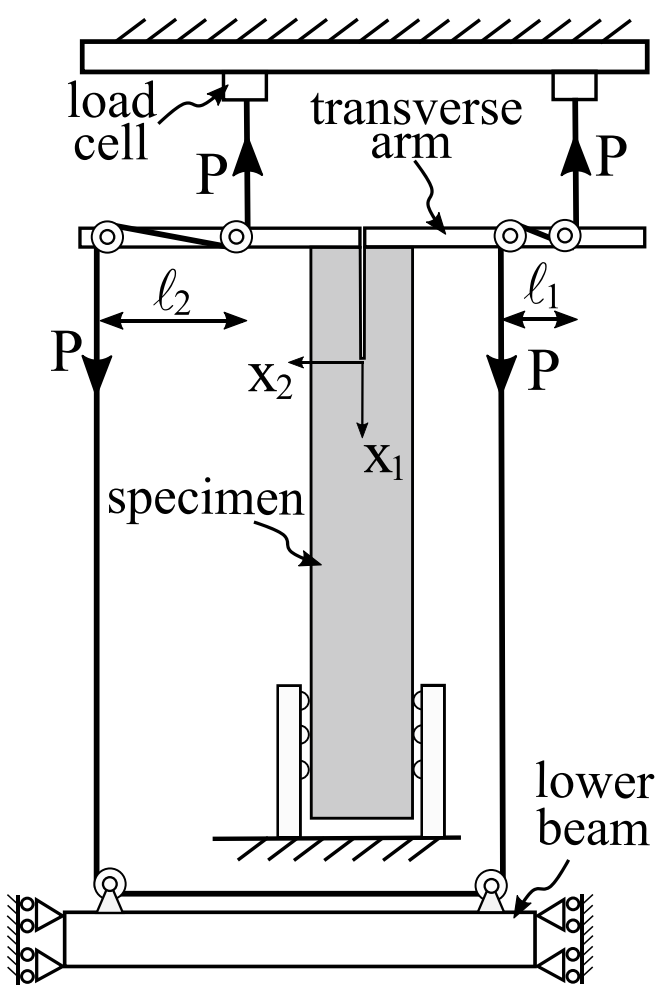

(a)

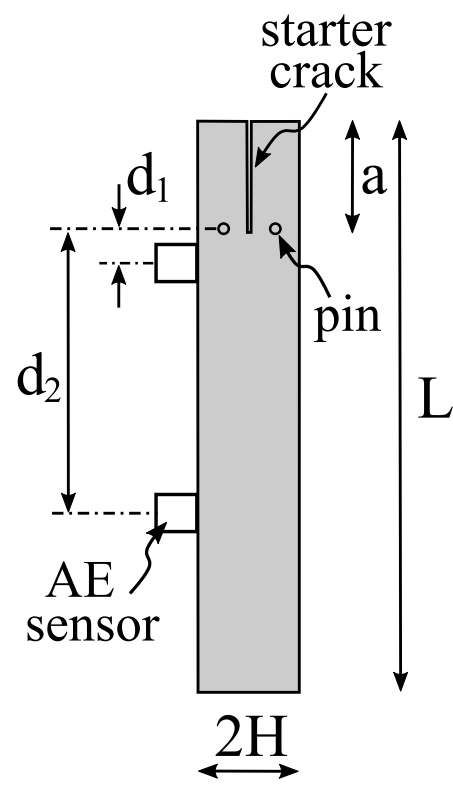

(b) 
as a function of the applied load (see Fig. 3 ), $\Delta^{*}$ was calculated.

Crack growth initiation was detected visually assisted by the non-linearity of the $J \Delta^{*}$ relationship and the acoustic emission activity with time. This value of the fracture energy, i.e. for crack initiation, is denoted as $J_{i n}$. It should be emphasised that with this procedure, crack initiation is detected once the crack is approximately opened by 20-40 $\mu \mathrm{m}$. More precise crack initiation detection should involve testing of the DCB specimens at the microscale e.g. inside a scanning electron microscope [23].

\subsection{Acoustic emission}

Two R15 $\alpha$ narrow band resonant piezoelectric sensors from Physical Acoustics Corporation were mounted on the surface of the DCB specimens (see Fig. 2b). One sensor was placed close to the initial crack $\left(d_{1}=10 \mathrm{~mm}\right)$ and the second sensor at a large distance $\left(d_{2}=260 \mathrm{~mm}\right)$. The sensors were used with the Micro-II Express acquisition system and the AEwin ${ }^{T M}$ software from Physical Acoustics Corporation and includes a preamplifier. The AEwin ${ }^{T M}$ software has the capability of reducing the AE signals into a set of features such as amplitude, rise time, duration, energy and counts as shown in Fig. 4.

In this paper, the AE temporal features (Fig. 4) are used to investigate the acoustic signature difference with the mode mixity. Other complex signal features such as a combination of the features of Fig. 4 [24] or features from the signals frequency domain $[25,26]$ are not considered since separating the $A E$ signals into groups or clusters $[27,28]$ is outside the scope of the present study. The basic AE features shown in Fig. 4 have been used to correlate acoustic emission data to damage in composite materials [29-31].

\section{Results}

Figure 5 shows the fracture energy, $J_{R}$, as function of the end-opening, $\Delta^{*}$, for four mode mixities $0^{\circ}, 41^{\circ}, 58^{\circ}$ and $88^{\circ}$. The cumulative acoustic events from $A E$ sensor 1 are
Fig. 3 Series of images, extracted from a video recording, for a DCB specimen with $\psi=0^{\circ}\left(M_{1} / M_{2}=-1\right)$. A point on each beam of the $D C B$ specimen is tracked by digital image correlation to measure the end-opening $\Delta^{*}$

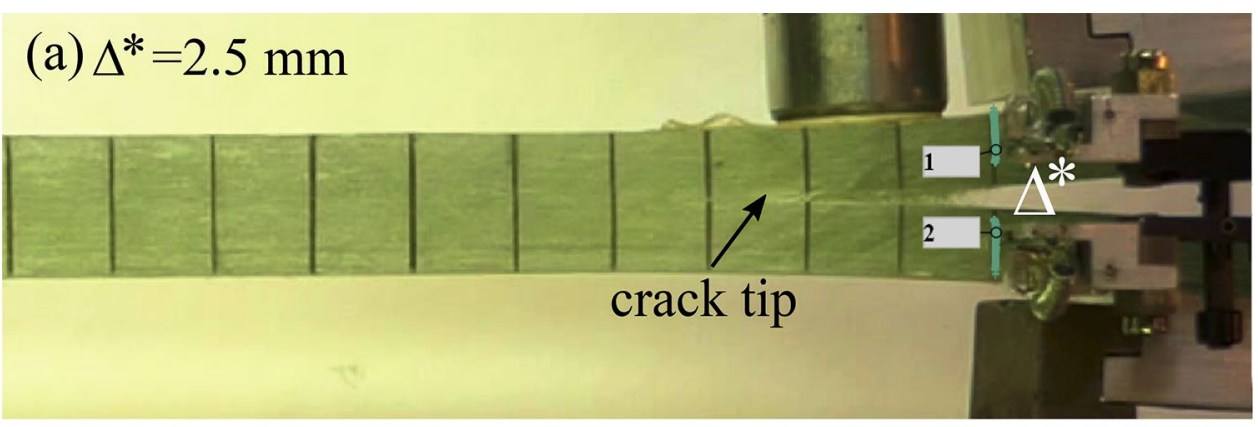

(b) $\Delta^{*}=5 \mathrm{~mm}$

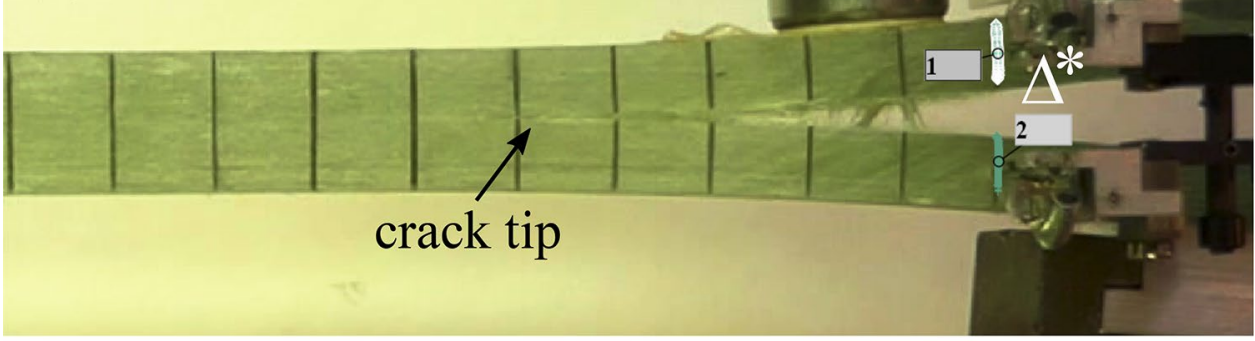

(c) $\Delta^{*}=8 \mathrm{~mm}$

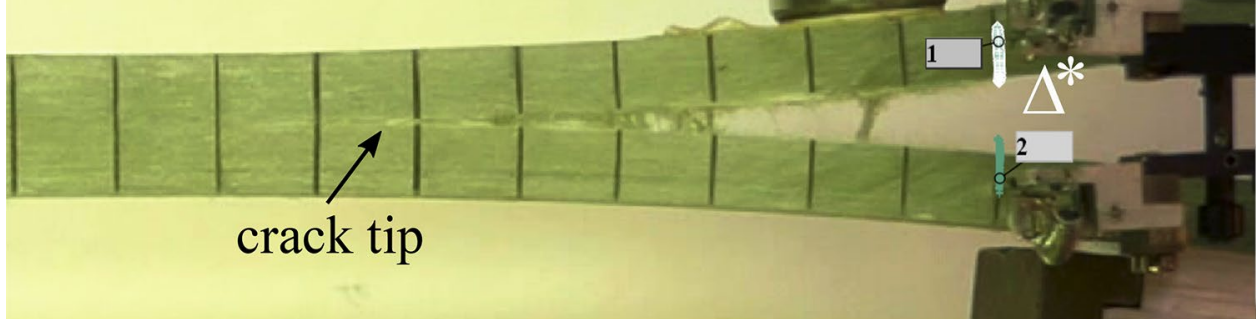



Emission (AE) signal with the waveform descriptors calculated by the acquisition system for each $A E$ event
Fig. 4 A schematic Acoustic

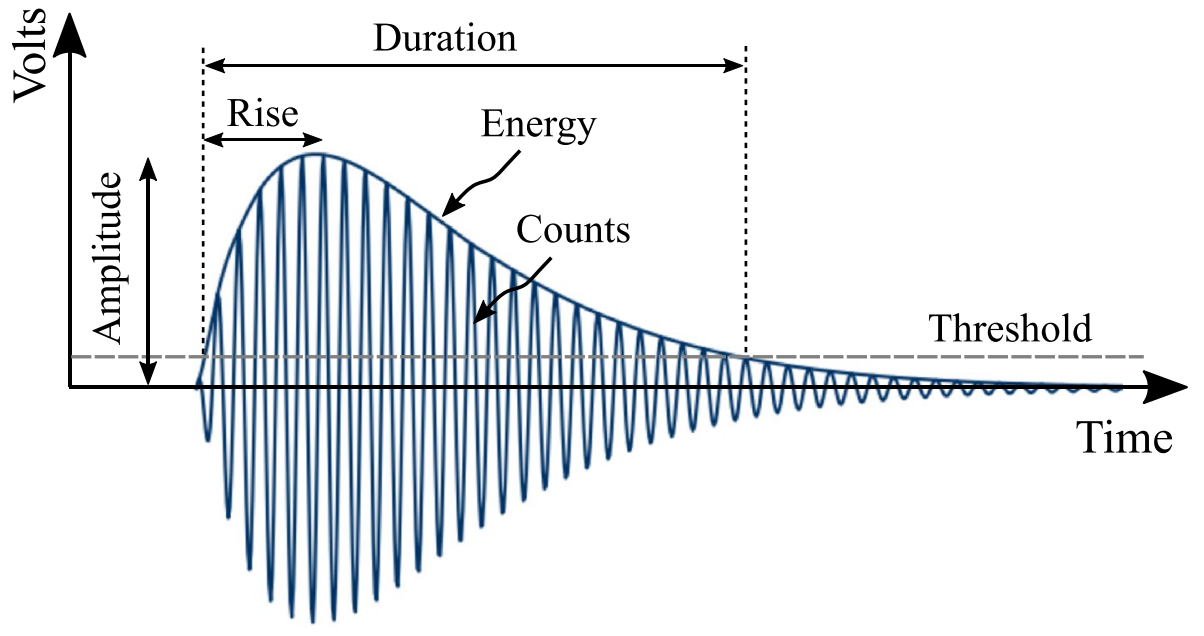

Fig. 5 Fracture energy, $J_{R^{\prime}}$ and cumulative $A E$ events ( $A E$ sensor 1 ) as a function of the end-opening, $\Delta^{*}$, for different mode mixities. $\Delta t=0.05$ $s, M_{1} / M_{2}=-1 \rightarrow \psi=0^{\circ}$, $M_{1} / M_{2}=0 \rightarrow \psi=41^{\circ}$ $M_{1} / M_{2}=0.30 \rightarrow \psi=58^{\circ}$ and $M_{1} / M_{2}=0.94 \rightarrow \psi=88^{\circ}$

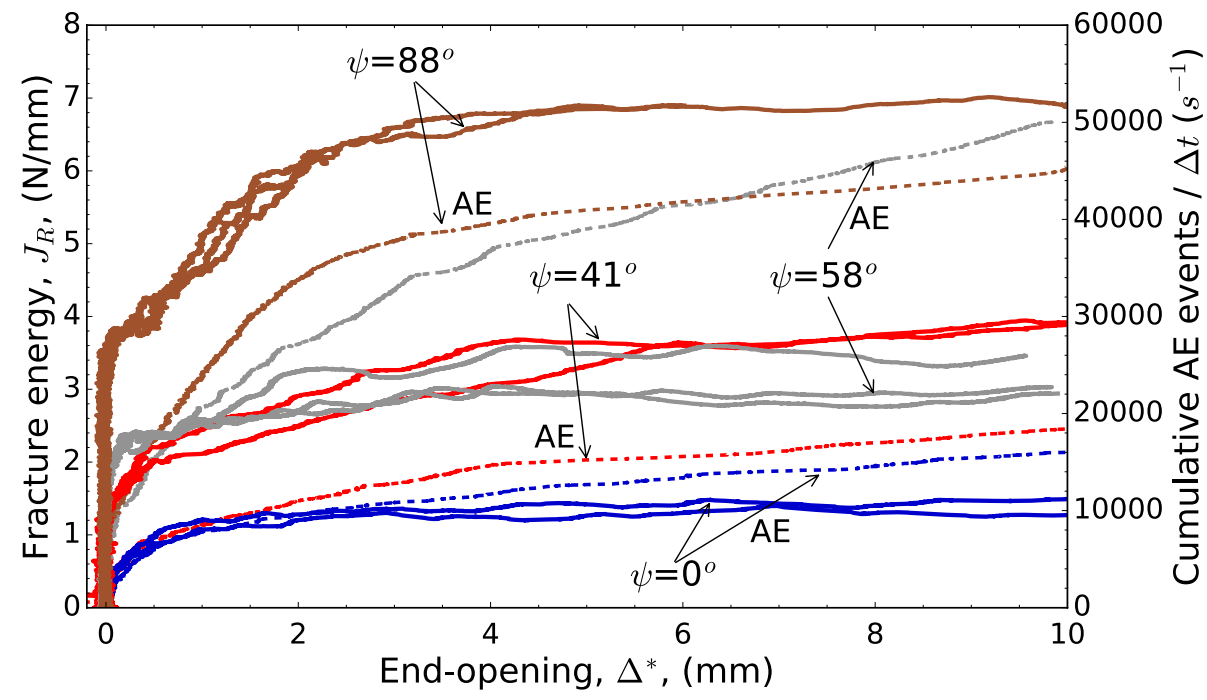

also plotted (dashed lines) as function of the opening $\Delta^{*}$ for a one specimen for each mode mixity. Each point represents the acoustic events occurred within $0.05 \mathrm{~s}$, which corresponds to the applied moments acquisition frequency.

With increasing the applied load (moments), the crack tip moved along the specimen length $\left(x_{1}\right)$. As $\Delta^{*}$ increased, the fracture energy approached a steadystate value, $J_{s s}$, for all mode mixities. The cumulative acoustic events follow in a good agreement the fracture energy curves. The cumulative acoustic events increased rapidly up to the onset of the non-linearity of the $J_{R^{-}}$ $\Delta^{*}$ curves. The non-linearity is associated with the crack growth initiation. Then, similar to the fracture energy, they approached a constant rate for large values of $\Delta^{*}$. Is interesting to observe that the number of cumulative acoustic events is very similar for $\psi=0^{\circ}$ and $41^{\circ}$, and approximately 3 times smaller than for large mode mixities $\left(\psi=58^{\circ}\right.$ and $\left.88^{\circ}\right)$.

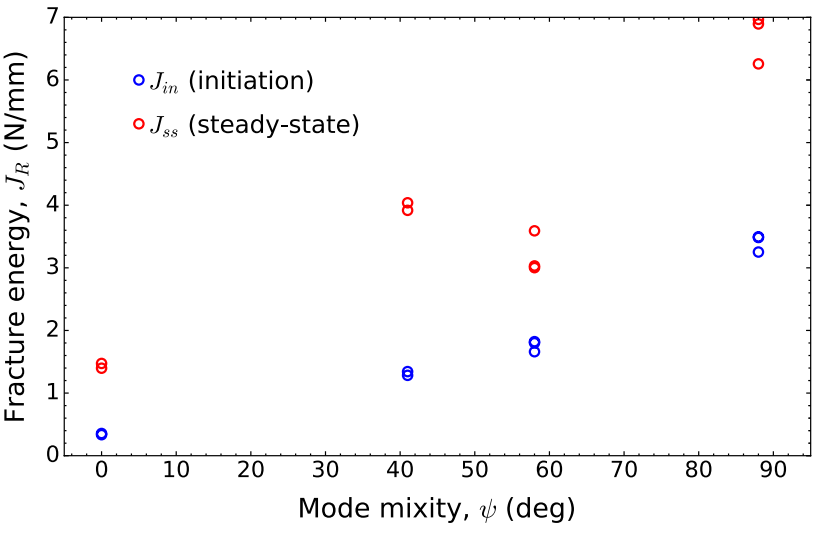

Fig. 6 Crack growth initiation value, $J_{i n}$, and steady-state fracture energy, $J_{s s}$, as a function of the mode mixity, $\psi$ 
The crack growth initiation and steady-state values of $J_{R}$ with the mode mixity, $\psi$, are summarised in Fig. 6 . The fracture energy at the initiation of crack growth, $J_{\text {in }}$ increases with increasing $\psi$ in agreement with earlier studies on various material systems $[22,32-34]$. For $\psi=88^{\circ}, J_{\text {in }}$ is approximately 10 times the $J_{i n}$ value for $\psi=0^{\circ}$.

The steady-state fracture energy, $J_{s s}$ does not increase continuously with $\psi$. $J_{s s}$ for $\psi=41^{\circ}$ is larger than $J_{s s}$ for $\psi=58^{\circ}$. This highlights the importance of mix mode testing. Relying only on pure mode I and mode II tests and then interpolate the fracture energy between the mode I and mode II values can result in incorrect variation of the fracture energy with mode mixity. $J_{s s}$ for $\psi=88^{\circ}$ is about 4.5 times larger than $J_{s s}$ for $\psi=0^{\circ}$.

Figures 7, 8, 9, 10 and 11 show the fracture energy curves as a function of the end-opening $\Delta^{*}$ for $\psi=0^{\circ}$, $41^{\circ}, 58^{\circ}$ and $88^{\circ}$, respectively. In contrast to Fig. 5 , the acoustic emission events (from AE sensor 1 ) occurred in a time interval $\Delta t$ equal to $0.05 \mathrm{~s}$ (equal to the acquisition time interval for the moments) are plotted instead of the cumulative acoustic emission events. For all mode mixities, the number of acoustic emission events per $\Delta t$ increases rapidly as the moments increase and reaches a plateau value when the non-linearity of the $J_{R}-\Delta^{*}$ curves occurs. It is interesting to observe that the maximum number of acoustic events per $\Delta t$ is of the same order for all mode mixities.

For the mode I $\left(\psi=0^{\circ}\right)$ there are several time intervals where the number of acoustic emission events drops to zero or well below 9 to 11 events. This is an indication of a non-uniform fracture process zone. In many instances, the drop of the number of acoustic events is attributed to a decrease of $J_{R}$ occurring when the DCB specimen partially unloads due to crack growth. The partial unloading
Fig. 7 Fracture energy, $J_{R}$, and $A E$ events ( $A E$ sensor 1 ) as a function of the end-opening, $\Delta^{*}$, for $\psi=0^{\circ}\left(M_{1} / M_{2}=-1\right)$. Every $A E$ point is the sum of acoustic events in time interval $\Delta t=0.05 \mathrm{~s}$

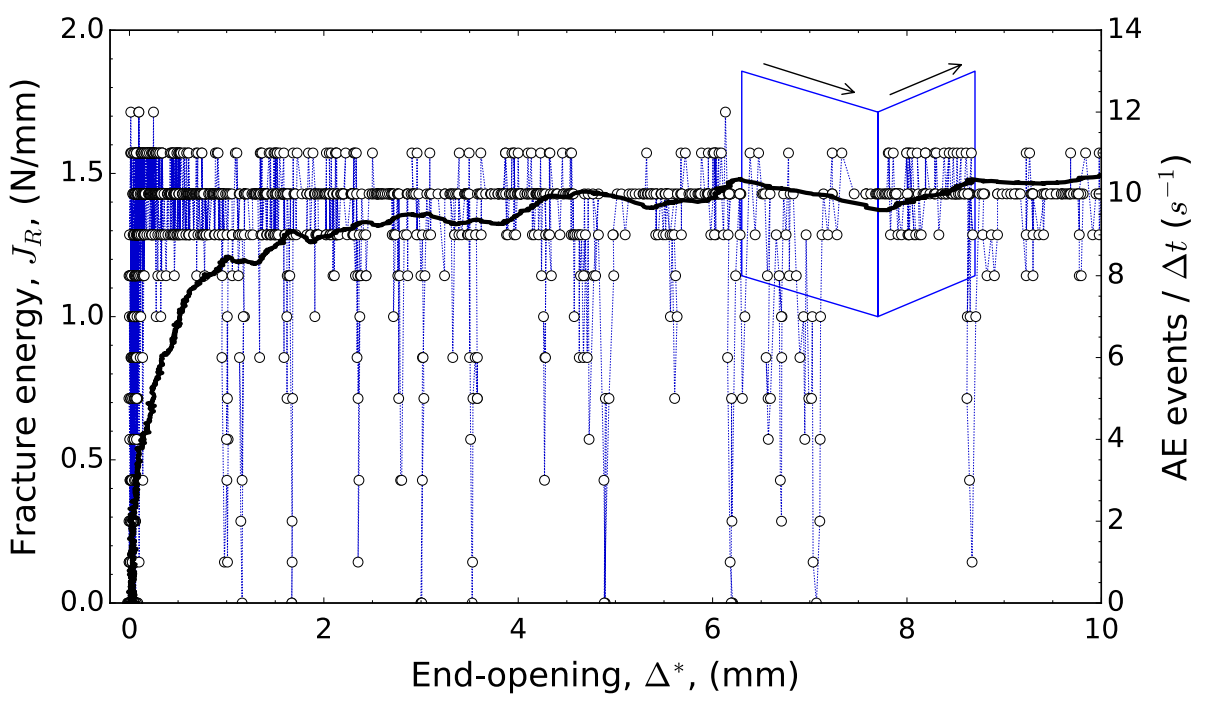

Fig. 8 Fracture energy, $J_{R}$, and $A E$ events ( $A E$ sensor 1 ) as a function of the end-opening, $\Delta^{*}$, for $\psi=41^{\circ}\left(M_{1} / M_{2}=0\right)$. Every $A E$ point is the sum of acoustic events in time interval $\Delta t=0.05 \mathrm{~s}$

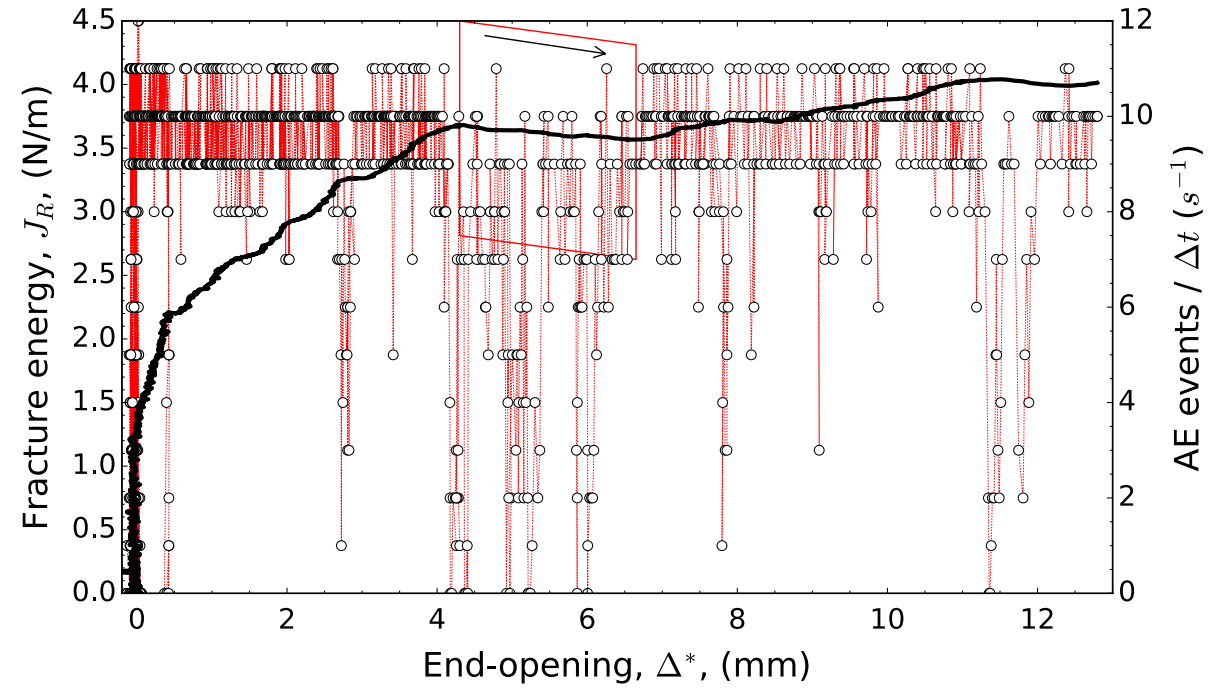


Fig. 9 Series of images, extracted from a video recording, for a DCB specimen with $\psi=41^{\circ}\left(M_{1} / M_{2}=0\right)$ showing the crack tip and fracture process zone
Fig. 10 Fracture energy, $J_{R}$, and $A E$ events (AE sensor 1 ) as a function of the end-opening, $\Delta^{*}$, for $\psi=58^{\circ}\left(M_{1} / M_{2}=0.30\right)$ Every $A E$ point is the sum of acoustic events in time interval $\Delta t=0.05 \mathrm{~s}$
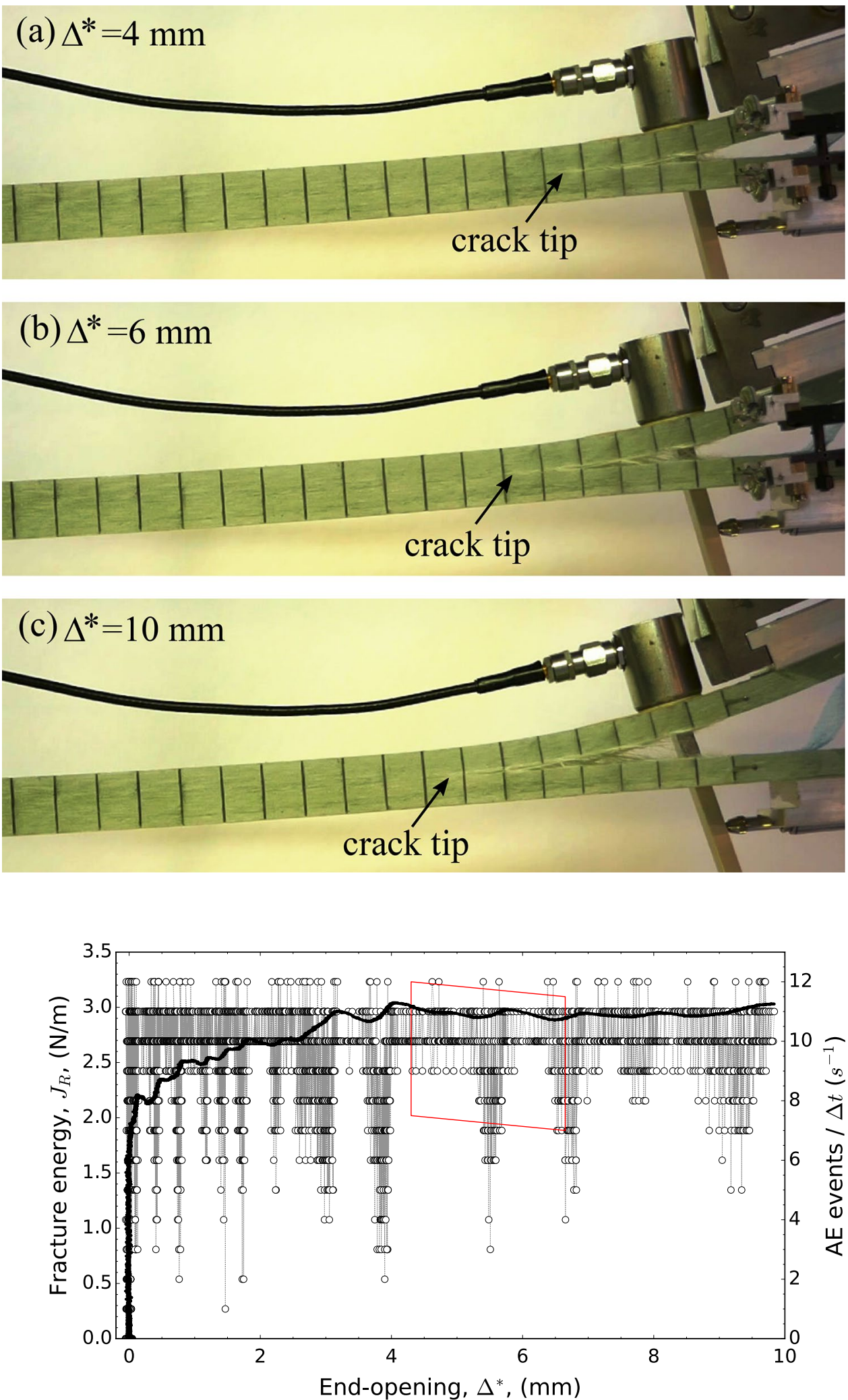

of the DCB specimen is due to the constant rotation rate by which the experiments are conducted. Such a region of unloading is enclosed by the first rectangular in Fig. 7 where acoustic activity is relatively lower. Unloading is followed by loading ( $J_{R}$ increases) and the acousticemission activity increases again as shown in the region enclosed 
Fig. 11 Fracture energy, $J_{R}$, and $A E$ events ( $A E$ sensor 1 ) as a function of the end-opening, $\Delta^{*}$, for $\psi=88^{\circ}\left(M_{1} / M_{2}=0.94\right)$. Every $A E$ point is the sum of acoustic events in time interval $\Delta t=0.05 \mathrm{~s}$

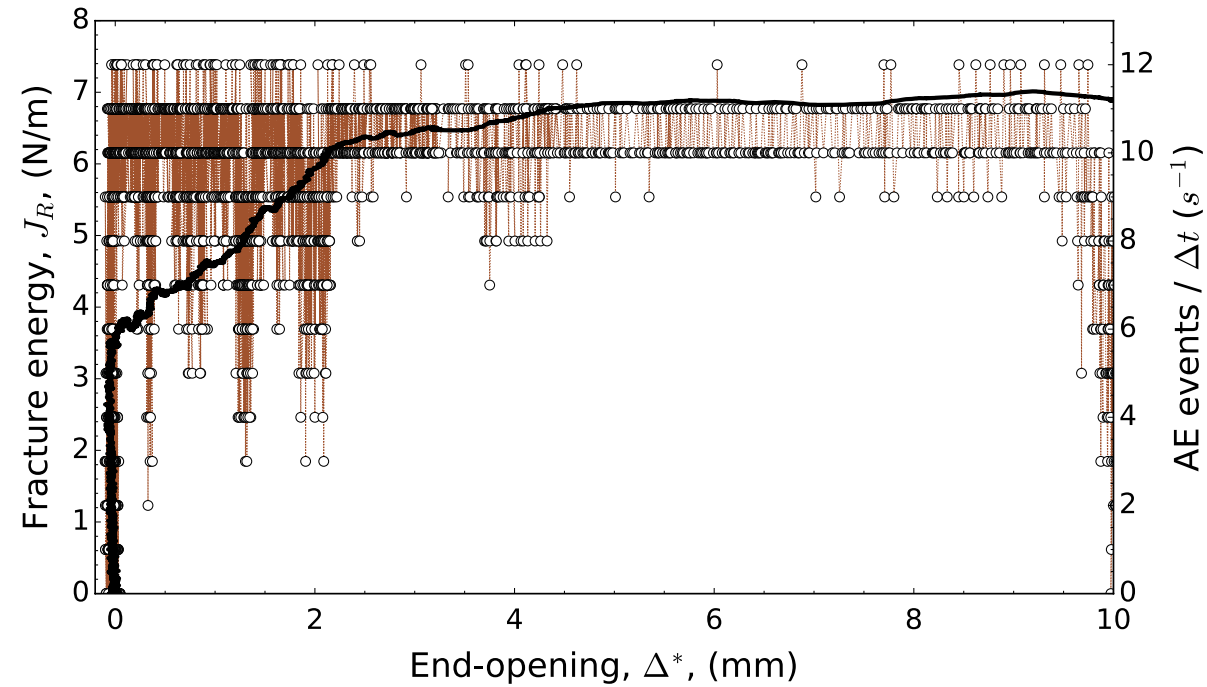

by the second rectangular. Images of the fracture process zone development with increasing $\Delta^{*}$ are shown in Fig. 3. It can bee seen that the fracture process zone is not uniform. There are areas with fibres or bundles of fibres connecting the crack faces and areas where the crack faces are not bridged by fibres. These observations are in agreement with the acoustic emission events pattern of Fig. 11.

For $\psi=41^{\circ}$ (Fig. 8), some differences in the acoustic emission events, compared to the mode I, can be observed. The time intervals where the number of acoustic emission events is low are fewer and most likely are associated with partial unloading of the specimen. Such a region of specimen unloading is enclosed by a rectangular (Fig. 8). Within this region (time interval), the number of acoustic events drops even to zero.

Figure 9 shows the fracture process zone for $\psi=41^{\circ}$ with increasing $\Delta^{*}$. Compared to $\psi=0^{\circ}$ (Fig. 3), the fracture process zone is more uniform e.g. fibres or bundles of fibres connect the crack faces without regions where there are no bridging fibres. It is interesting also to observe the different orientation of the bridging fibres between $\psi=0^{\circ}$ and $\psi=41^{\circ}$.

Whereas the acoustic events for $\psi=0^{\circ}$ and $\psi=41^{\circ}$ are very similar, significant differences can be observed for $\psi=58^{\circ}$ shown in Fig. 10. There are no time intervals where the number of acoustic emission events drops to zero and there are fewer regions where a decrease in the number of acoustic emission events is observed. The average number of acoustic events per $\Delta t$ is slightly higher than for $\psi=0^{\circ}$ and $\psi=41^{\circ}$ but more importantly the density of the AE points in Fig. 10 is about 2.5-3 times higher than in Figs. 7 and 8. This is because the duration of the experiments for $\psi=58^{\circ}$ is approximately $2.5-3$ times longer than for $\psi=0^{\circ}$ and $\psi=41^{\circ}$. It is mainly for this reason, that the cumulative $\mathrm{AE}$ events for $\psi=58^{\circ}$ are approximately 3 times (at steady-state) higher than $\psi=0^{\circ}$ and $\psi=41^{\circ}$ (see Fig. 5).

The number of acoustic emission events per $\Delta t$ for $\psi=88^{\circ}$ (Fig. 11) presents similarities with $\psi=58^{\circ}$. However, there are even fewer regions where the number of acoustic emission events drops and these regions are mainly in the rising part of the fracture energy curve. It is interesting to observe that in the steady-state region the number of acoustic events per time interval is remarkably constant. Only for very large end-openings, the number acoustic emission events drops. It should be mentioned that the duration of the $\psi=88^{\circ}$ experiments was shorter than for $\psi=58^{\circ}(\approx 15 \%)$. On the other hand, the average number of acoustic emission events is slightly higher than for $\psi=58^{\circ}$. As a result, the cumulative AE events, at steady-state, for $\psi=88^{\circ}$ is slightly lower than for $\psi=58^{\circ}$.

The fracture process zone for $\psi=88^{\circ}$ (near mode II) with increasing end-opening, $\Delta^{*}$ is shown in Fig. 12. A clear difference with respect to the mode I dominated fracture process zones (Figs. 3, 9) can be observed. For $\psi=88^{\circ}$, the fracture process zone is much larger in length and the fibre bridging pattern within the fracture process zone is very uniform. This is in agreement with the results presented above showing a much larger end-opening to attain the steady-state fracture energy (Fig. 5), large number of cumulative acoustic emission events (Fig. 5) and approximately constant number of acoustic emission events per time interval (Fig. 11).

Figure 13 shows the scatter plots of amplitude versus duration for the linear part (prior to the initiation of crack growth) of the fracture energy for $\psi=0^{\circ}, \psi=41^{\circ}, \psi=58^{\circ}$ and $\psi=88^{\circ}$, respectively. This plot does not show a clear difference between the different mode mixities. In all cases the AE signals have a low amplitude and low duration. The number of $A E$ signals with amplitude in the area of $100 \mathrm{~dB}$ 
Fig. 12 Series of images, extracted from a video recording, for a DCB specimen with $\psi=88^{\circ}\left(M_{1} / M_{2}=0.94\right)$ showing the crack tip and fracture process zone

Fig. $13 \mathrm{AE}$ results in the amplitude-duration projection for the linear part of the fracture energy, $J_{R_{c r}}$ curve under different mode mixities: a $\Delta^{*} \in[0.0-0.05]$, b $\Delta^{*} \in[0.0-0.04]$, $\mathbf{c} \Delta^{*} \in[0.0-0.04], \mathbf{d}$ $\Delta^{*} \in[0.0-0.04]$

and long duration time ( $>10 \mathrm{~ms}$ ) is very small. AE signals with such characteristics are present only for mode mixities of $\psi=0^{\circ}$ and $\psi=41^{\circ}$.
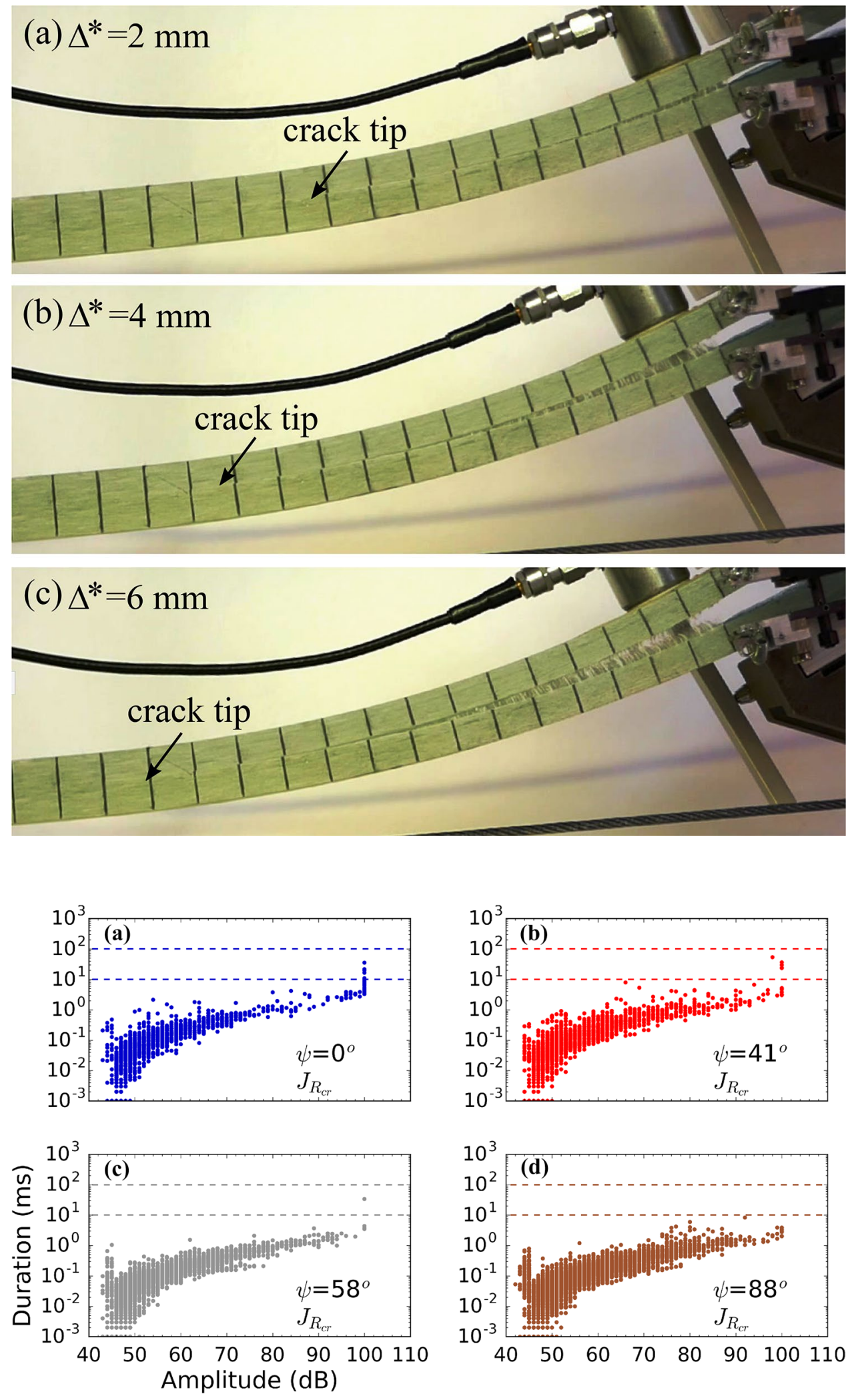

A small difference between the four mode mixities can be observed in the scatter plots of duration versus rise time (Fig. 14). AE signals with long duration time (> $10 \mathrm{~ms}$ ) 
Fig. $14 \mathrm{AE}$ results in the duration-rise time projection for the linear part of the fracture energy, $J_{R_{c r}}$ curve under different mode mixities: a $\Delta^{*} \in[0.0-0.05]$, b $\Delta^{*} \in[0.0-0.04]$, c $\Delta^{*} \in[0.0-0.04], \mathbf{d}$ $\Delta^{*} \in[0.0-0.04]$
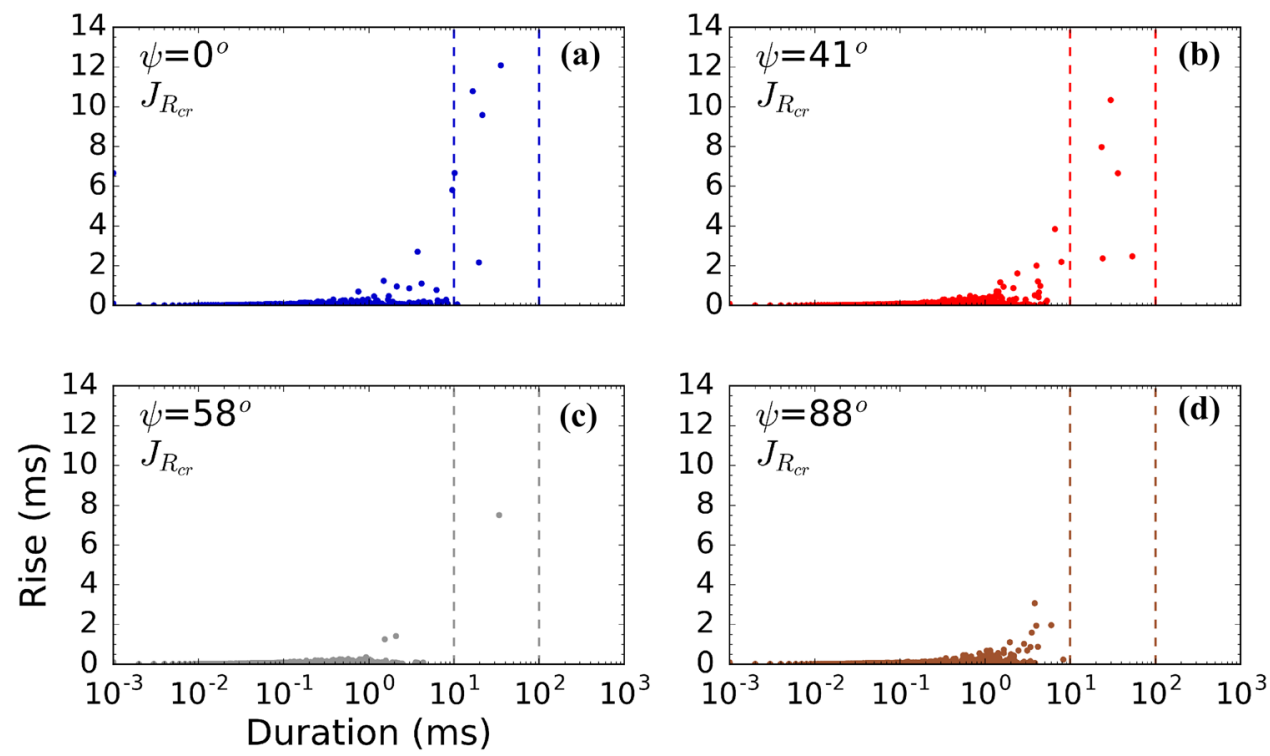

and long rise time ( $>5 \mathrm{~ms}$ ) are observed only for the mode I dominated applied mode mixities $\left(\psi=0^{\circ}\right.$ and $\left.\psi=41^{\circ}\right)$.

Next, in Figs. 15 and 16 the scatter plots of amplitude versus duration for the rising and steady-state parts of the fracture energy are plotted for the four different mode mixities. A clear difference exists between the mode I dominated $D C B$ specimens and mode mode II dominated specimens $\left(\psi=58^{\circ}\right.$ and $\left.\psi=88^{\circ}\right)$ in the rising part of the fracture energy curves (Fig. 15). The number of AE signals with an amplitude larger than $90 \mathrm{~dB}$ is much larger when $\psi=0^{\circ}$ or $\psi=41^{\circ}$ than when $\psi=58^{\circ}$ or $\psi=88^{\circ}$. AE signals with duration longer than $10 \mathrm{~ms}$ are present only for $\psi=0^{\circ}$ or $\psi=41^{\circ}$. It is interesting to observe that the strongest AE activity (large amplitude and long duration) is for $\psi=41^{\circ}$. In the steady-state part of the fracture energy curves, the overall pattern in the amplitude-duration projection does not change significantly for $\psi=0^{\circ}$ and $\psi=41^{\circ}$. There are more AE signals with large amplitude and in particular long duration time. As in the rising part, this is more pronounced for $\psi=41^{\circ}$. At the same time, there are fewer $A E$ signals with low amplitude and short duration time compared to the rising part of the fracture energy. More obvious differences between the rising part and the steady-state part of the fracture energy curves are observed for the mode II dominated DCB specimens and in particular for the near mode ll case $\left(\psi=88^{\circ}\right)$. The number of $A E$ signals with large amplitude and long duration time is significantly reduced.

Figures 17 and 18 show the scatter plots of duration versus rise time for the rising part and steady-state parts of
Fig. $15 \mathrm{AE}$ results in the amplitude-duration projection for the non-linear part of the fracture energy, $J_{R_{\text {in }}}$, curve under different mode mixities: a $\Delta^{*} \in[0.05-1.06]$, b $\Delta^{*} \in[0.04-4.30]$, c $\Delta^{*} \in[0.04-3.15], \mathbf{d}$ $\Delta^{*} \in[0.04-2.51]$
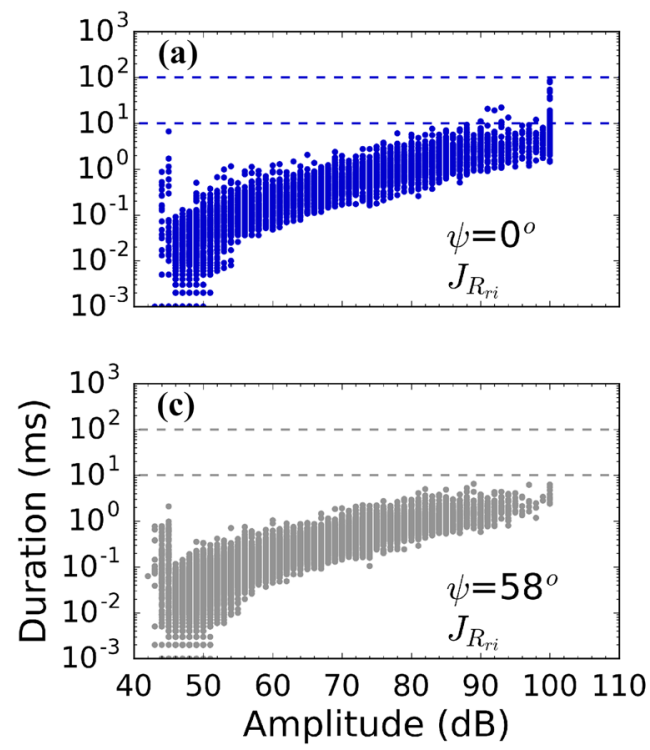
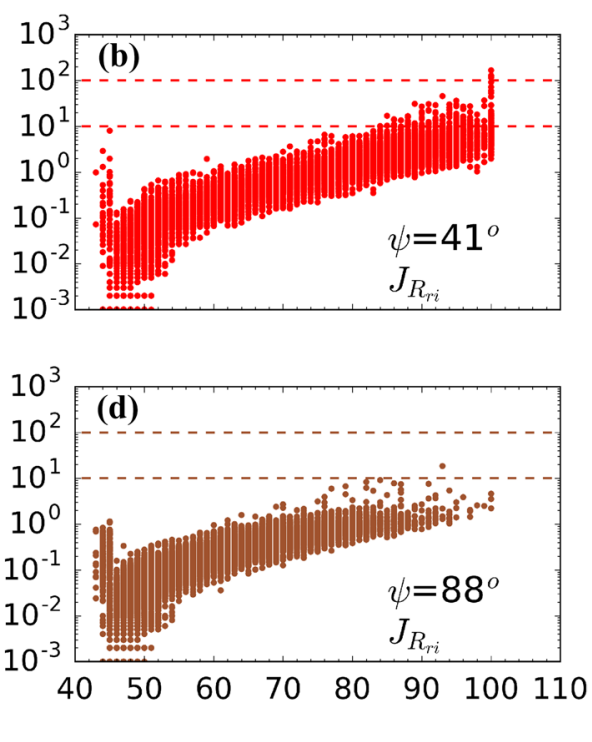
Fig. $16 \mathrm{AE}$ results in the amplitude-duration projection for the steady-state part of the fracture energy, $J_{R_{s s^{\prime}}}$ curve under different mode mixities: a $\Delta^{*} \in[4.34-8.67]$, b $\Delta^{*} \in[4.40-11.60]$, c $\Delta^{*} \in[4.17-9.71], \mathbf{d}$ $\Delta^{*} \in[4.45-9.24]$
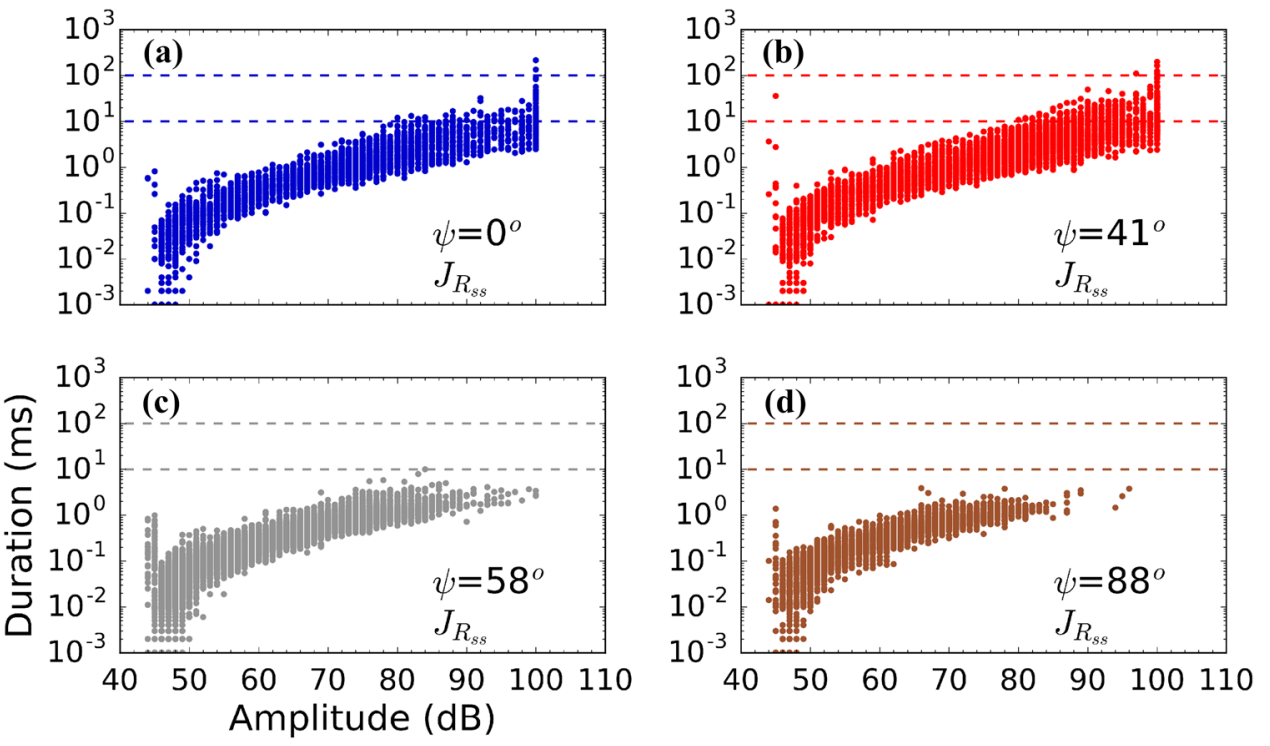

Fig. $17 \mathrm{AE}$ results in the duration-rise time projection for the non-linear part of the fracture energy curve, $J_{R_{i r^{\prime}}}$ under different mode mixities: a $\Delta^{*} \in[0.05-1.06]$, b $\Delta^{*} \in[0.04-4.30]$, c $\Delta^{*} \in[0.04-3.15], \mathbf{d}$ $\Delta^{*} \in[0.04-2.51]$
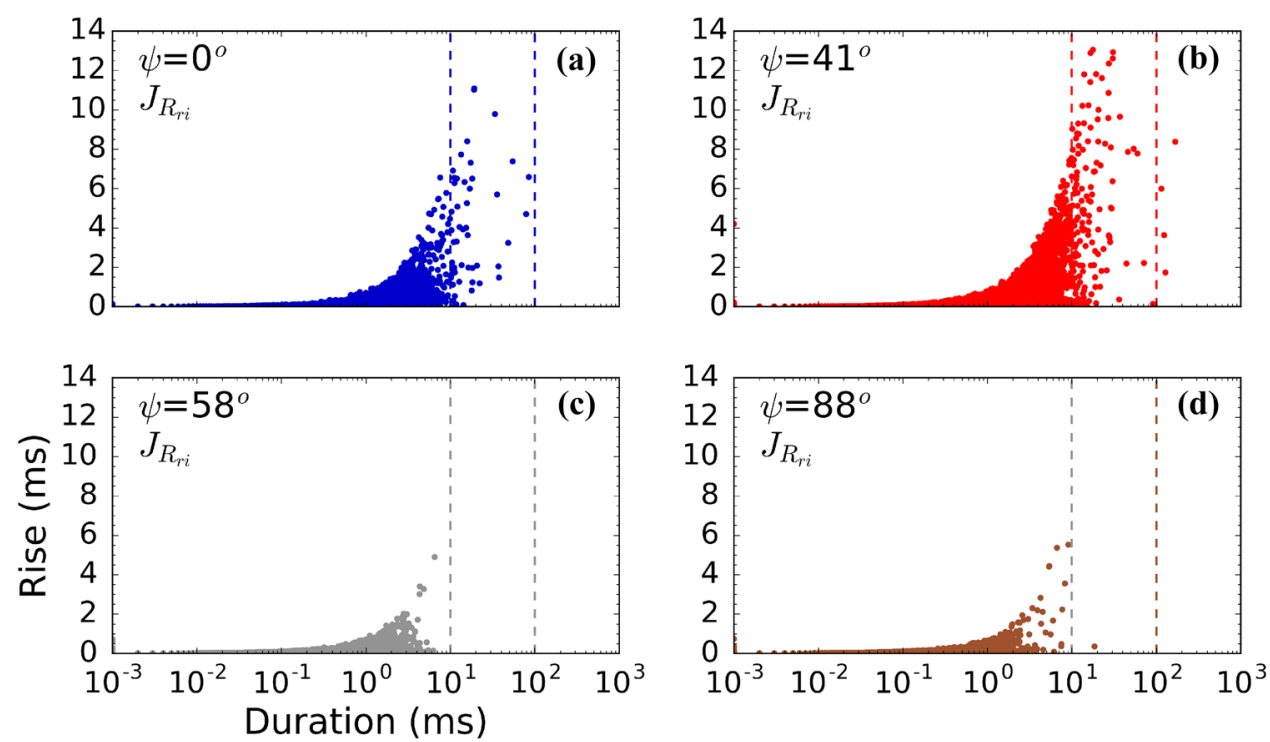

the fracture energy curves, respectively, for the four mode mixities. The differences between the mode I dominated DCB's $\left(\psi=0^{\circ}\right.$ or $\left.\psi=41^{\circ}\right)$ and the mode II dominated DCB's $\left(\psi=58^{\circ}\right.$ or $\left.\psi=88^{\circ}\right)$ are even more pronounced compared to Figs. 15 and 16 . In the rising part of the fracture energy curves and for $\psi=0^{\circ}$ or $\psi=41^{\circ}$, there is a large number of $A E$ signals with long duration and long rising time. Especially for $\psi=41^{\circ}$, there are AE signals with a duration time larger than $100 \mathrm{~ms}$. In contrast, for $\psi=58^{\circ}$ or $\psi=88^{\circ}$, there are no AE signals with a duration larger than $10 \mathrm{~ms}$ or a rising time longer than $6 \mathrm{~ms}$. In the steadystate part of the fracture energy curves and for $\psi=0^{\circ}$ and in particular for $\psi=41^{\circ}$, the number of $A E$ signals with long duration and long rising times increases significantly compared to the rising part of the fracture energy curves.
For a mode mixity equal to $\psi=58^{\circ}$, there is almost no significant difference between the rising and the steady-stare part of the fracture energy curves. However, for $\psi=88^{\circ}$ (near mode II), a significant decrease of AE signals with large duration and long rising time is observed between the rising and the steady-state part of the fracture energy curve. In the steady-state part, the duration of the AE signals is well below $10 \mathrm{~ms}$ and the rising time less than $2 \mathrm{~ms}$.

\section{Discussion}

Damage initiation, prior to crack growth initiation, can be successfully detected for any mode mixity using the $A E$ events. Acoustic emission events start to occur within 
Fig. $18 \mathrm{AE}$ results in the duration-rise time projection for the steady-state part of the fracture energy, $J_{R_{s s}}$, curve under different mode mixities: a $\Delta^{*} \in[4.34-8.67]$, b $\Delta^{*} \in[4.40-11.60]$, c $\Delta^{*} \in[4.17-9.71], \mathbf{d}$ $\Delta^{*} \in[4.45-9.24]$
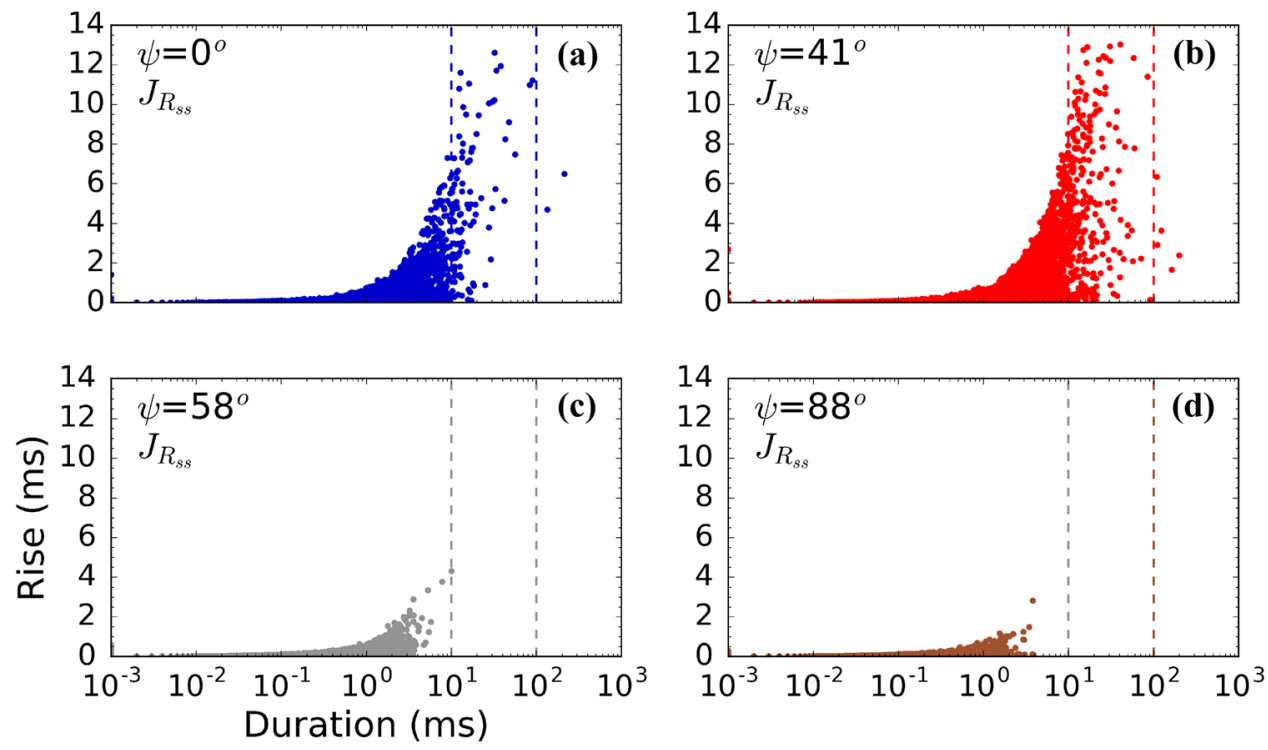

the linear part of the fracture energy curves indicating the presence of one or more damage mechanisms. However, it is not straightforward, in general, to use the AE events to differentiate the rinsing part from the steady-state part of the fracture energy curves since once the non-linearity starts, the number of acoustic events reaches a plateau value. In some cases however, e.g. for near mode II, this may be possible since at steady-state the number of $\mathrm{AE}$ events per time interval is fairly constant, in contrast to the rising part of the fracture energy curve where the number of $A E$ events may significantly drop in some time intervals.

Using the AE temporal features (Fig. 4), it is possible to clearly differentiate mode I from mode II dominated delaminations. Using the energy AE feature (Fig. 4) or other projections of $A E$ results than the ones presented here (amplitude versus duration or duration versus rise time) yielded similar results i.e. there was a clear difference between mode I and mode II dominated delaminations. Mode I dominated delaminations are characterised by presence of a large number of AE signals with high amplitude and long duration and rise time. On the other hand, for mode II dominated cracks, there are no AE signals with long duration and rise time or high amplitude. Long duration (>15 ms) and high amplitude AE events (in the range 75-90 dB) are typically associated with fibre breaks, whereas $A E$ events with a duration time less than $10 \mathrm{~ms}$ and amplitude in the $40-60 \mathrm{~dB}$ range are related to interface debonding $[35,36]$. Friction results in AE signals with duration in the order of $5 \mathrm{~ms}$. Additional failure mechanisms, with short duration and low amplitude, may include matrix cracking and failure of the stitching fibres (see Fig. 12). Thus, for any mode mixity, the AE signals related to fibre breakage is significantly less than for the other low amplitude, short duration failure mechanisms.
Similar findings were reported for glass/epoxy composites tested under mode I [26]. Interface debonding and friction are the main failure mechanisms contributing to the fracture energy. The contribution from fibre breakages (high energy) is limited due to their small number. The steadystate fracture energy for mode II is several times the mode I steady-state fracture energy. A much larger fracture process zone for near mode II (Fig. 3) compared to mode I (Fig. 12) will result in a significantly larger amount of dissipative failure mechanisms and thus to a larger steady-state fracture energy. As can be seen from Fig. 5, the AE events for near mode II is approximately 3 times larger than for mode I. As a next step, it would be interesting to apply pattern recognition techniques to detect and separate the $A E$ signals to clusters representing the different failure mechanisms mentioned above $[24,26,37,38]$.

Small variations from specimen to specimen, for the same loading conditions, were observed when the $A E$ events were plotted against the opening $\Delta_{*}$ e.g. Fig. 5 . More precisely, during crack propagation, the time intervals with low or no AE activity varied from specimen to specimen due to nearly always present variations within the bridging zone. However, the main characteristics of $\mathrm{AE}$ activity, i.e. duration versus amplitude or rise versus duration (Figs. 13, 14, 15, 16, 17, 18) were repeatable between DCB specimens under the same loading conditions. It should be noted that for the specific composite materials tested in the present work, due to the $90^{\circ}$ bundles (support threads), weak and relatively resin rich layers are present between the $0^{\circ}$ fibres. The delaminations initiate and grow mainly in these layers. Thus, local micro-structure variations, such as $0^{\circ}$ fibre positions, probably have a smaller effect on the $J$ and $A E$ observations for the same loading conditions compared to a pure unidirectional composite. 
All the $A E$ results presented in the previous section were from $A E$ sensor 1 (close to the initial crack). Using the $A E$ events from sensor 2 (far away from the crack tip even at steady-state) resulted in identical results (e.g. amplitude versus duration or duration versus rise time). The number of cumulative $\mathrm{AE}$ events was however in average $20 \%$ lower than the AE events detected from sensor 1.

In practice, most of the delamination cracks in a structure initiate and propagate under fatigue loading. Using $A E$ to detect and identify a growing, in particular mode II dominated, delamination, may be challenging since the $A E$ events will be characterised by even lower amplitudes and duration or rise times than the ones reported in the present work (static loading). Under fatigue, the AE signals from interface debonding or friction may be similar to the noise AE events (low amplitude and short duration [35]). A complex geometry or interaction with other failure mechanisms also adds to the identification estimation challenges.

A secondary finding of the present study is that the steady-state fracture energy does not continuously increase with increasing the mode mixity (Fig. 5). A common practice it is test composite materials under pure mode I and pure mode II and then use a mixed-mode fracture criterion $[32,39,40]$ to calculate the fracture energy at any mix-mode. Most mixed-mode fracture criteria predict a continuous increase of the fracture energy with the mode mixity. It is clear from Fig. 5 that this assumption is not general and that mixed mode experiments should be performed in a wide range of mode mixities. Moreover, mixed-mode fracture criteria are often used to formulate cohesive constitutive laws for finite element simulations of fracture. Using the same argument, it is more accurate to use directly the fracture energy dependence on mode mixity, such as the experimental results of Fig. 5, in the cohesive constitutive law [41], rather than using interpolation schemes between pure mode I and pure mode II.

In the previous section, the mode-mixity was described by $\psi$ which is strictly applicable to LEFM. For the composite material examined in the present work, fibre bridging results in a large fracture process zone. In this case, it is more appropriate to describe the mode mixity by the phase angle of openings, $\phi$, defined as the ratio of tangential to the normal opening [42]. Apart from the case of mode I (see Fig. 3) where $\phi=\psi$, for any other mode mixity $\phi \neq \psi$. Moreover, $\phi$ does not have a constant value but varies along the fracture process zone. This is clearly shown in Fig. 12 where it can be seen that at the actual crack tip, the crack is closed and loaded under mode II. Behind the crack tip and towards to the initial crack tip position, the normal opening component continuously increases i.e. there is an increasing mode I component. Every material point within the fracture process zone during the loading history experiences a varying mode mixity from near mode II to a mode I dominated mode mixity (see Fig. 12c). Even, there is a strong mode I component for $\psi=88^{\circ}$, this is not reflected in the AE events and $A E$ temporal features.

\section{Concluding remarks}

In the present work the acoustic emission characteristics of unidirectional glass/epoxy composites were investigated under different mode mixities using double cantilever beam specimens loaded with pure uneven bending moments. It was found that the number of acoustic events per time interval is the approximately the same for any mode mixity but the cumulative acoustic events are much larger for mode II dominated delaminations. Using simple acoustic emission temporal features, it was possible to correlate the mode mixity with the acoustic emission activity. For any mode mixity the fracture energy increase to a steady-state value was associated with low energy mechanisms such as friction or interface debonding. Fibre breakages were detected only in mode I dominated delaminations but their contribution to the fracture energy was minor.

Acknowledgements Leonardo Di Crescenzo is acknowledged for manufacturing the test specimens and Jan Sjølin for technical assistance in the mechanical testing.

Funding The work has received funding from the European Unions Horizon 2020 Research and Innovation Programme under Grant Agreement No 761072 (DACOMAT).

\section{Compliance with ethical standards}

Conflict of interest The author declares that he has no conflict of interest.

\section{References}

1. Hayman B (2007) Approaches to damage assessment and damage tolerance for FRP sandwich structures. J Sandw Struct Mater 9:571-596

2. Alderliesten RC (2015) Designing for damage tolerance in aerospace: a hybrid material technology. Mater Des 66:421-428

3. Homan JJ (2006) Fatigue initiation in fibre metal laminates. Int J Fatigue 28:366-374

4. Alderliesten RC (2007) Analytical prediction model for fatigue crack propagation and delamination growth in glare. Int $\mathrm{J}$ Fatigue 29:628-646

5. Chamis CC (2004) Probabilistic simulation of multi-scale composite behavior. Theor Appl Fract Mech 41:51-61

6. Chamis CC (2006) Probabilistic design of composite structures. Report ASA/TM2006-214660, NASA 
7. Sørensen JD (2009) Framework for risk-based planning of operation and maintenance for offshore wind turbines. Wind Energy 12:493-506

8. Sørensen JD, Toft HS (2010) Probabilistic design of wind turbines. Energies 3:241-257

9. McGugan M, Pereira G, Sørensen BF, Toftegaard H, Branner K (2015) Damage tolerance and structural monitoring for wind turbine blades. Philos Trans A 373:20140077

10. Schulte K, Baron C (1989) Load and failure analyses of CFRP laminates by means of electrical resistivity measurements. Compos Sci Technol 36:63-76

11. Ceysson O, Salvia M, Vincent L (1996) Damage mechanisms characterisation of carbon fibre/epoxy composite laminates by both electrical resistance measurements and acoustic emission analysis. Scripta Materialia 34:1273-1280

12. Guemes JA, Menéndez JM (2002) Response of bragg grating fiber-optic sensors when embedded in composite laminates. Compos Sci Technol 62:959-966

13. Sorensen L, Botsis J, Gmür T, Humbert L (2008) Bridging tractions in mode I delamination: measurements and simulations. Compos Sci Technol 68:2350-2358

14. Stutz S, Cugnoni J, Botsis J (2011) Studies of mode I delamination in monotonic and fatigue loading using FBG wavelength. Compos Sci Technol 71:443-449

15. Sawan HA, Walter ME, Marquette B (2015) Unsupervised learning for classification of acoustic emission events from tensile and bending experiments with open-hole carbon fiber composite samples. Compos Sci Technol 107:89-97

16. Goutianos S, Sørensen BF (2016) Fracture resistance enhancement of layered structures by multiple cracks. Eng Fract Mech 151:92-108

17. Sørensen BF, Goutianos S, Jacobsen TK (2009) Strength scaling of adhesive joints in polymer-matrix composites. Int J Solids Struct 46:741-761

18. Dzenis YA, Saunders I (2002) On the possibility of discrimination of mixed mode fatigue fracture mechanisms in adhesive composite joints by advanced acoustic emission analysis. Int J Fract 117:L23-L28

19. Goutianos S, Sørensen BF (2012) Path dependence of truss-like mixed mode cohesive laws. Eng Fract Mech 91:117-132

20. Sørensen BF, Jørgensen K, Jacobsen TK, Østergaard RC (2006) DCB-specimen loaded with uneven bending moments. Int J Fract 141:163-176

21. Rice JR (1968) A path independent integral and the approximate analysis of strain concentrations by notches and cracks. J Appl Mech 35:379-386

22. Sørensen BF, Jacobsen TK (2009) Characterizing delamination of fibre composites by mixed mode cohesive laws. Compos Sci Technol 69:445-456

23. Goutianos S, Arévalo R, Sørensen BF, Peijs T (2014) Effect of processing conditions on fracture resistance and cohesive laws of binderfree all-cellulose composites. Appl Compos Mater 21:805-825

24. Philippidis TP, Nikolaidis VN, Anastassopoulos AA (1998) Damage characterization of carbon/carbon laminates using neural network techniques on AE signals. NDT\&E Int 31:329-340

25. Marec A, Thomas JH, El Guerjouma R (2008) Damage characterization of polymer-based composite materials: multivariable analysis and wavelet transform for clustering acoustic emission data. Mech Syst Signal Process 22:1441-1464
26. Sause MGR, Müller T, Horoschenkoff A, Horn S (2012) Quantification of failure mechanisms in mode-i loading of fiber reinforced plastics utilizing acoustic emission analysis. Compos Sci Technol 72:167-174

27. Godin N, Huguet S, Gaertner R, Salmon L (2004) Clustering of acoustic emission signals collected during tensile tests on unidirectional glass/polyester composite using supervised and unsupervised classifiers. NDT\&E Int 37:253-264

28. Li L, Lomov SV, Yan X (2015) Correlation of acoustic emission with optically observed damage in a glass/epoxy woven laminate under tensile loading. Compos Struct 123:45-53

29. Barré S, Benzeggagh ML (1994) On the use of acoustic emission to investigate damage mechanisms in glass-fibre-reinforced polypropylene. Compos Sci Technol 52:369-376

30. Bohse J (2000) Acoustic emission characteristics of micro-failure processes in polymer blends and composites. Compos Sci Technol 60:1213-1226

31. Fotouhi M, Suwarta P, Jalalvand M, Czel G, Wisnom MR (2016) Detection of fibre fracture and ply fragmentation in thin-ply UD carbon/glass hybrid laminates using acoustic emission. Composites A 86:66-76

32. Benzeggagh ML, Kenane M (1996) Measurement of mixed-mode delamination fracture toughness of unidirectional glass/epoxy composites with mixed-mode bending apparatus. Compos Sci Technol 56:439-449

33. Liang YM, Liechti KM (1995) Toughening mechanisms in mixedmode. Int J Solids Struct 32:957-978

34. Swadener JG, Liechti KM, Liang YM (2002) Shear induced toughening in bonded joints: experiments and analysis. Int J Fract 114:113-132

35. Ageorges C, Friedrich K, Schüller T, Lauke B (1999) Single-fibre Broutman test: fibrematrix interface transverse debonding. Composites A 30:1423-1434

36. Schüller T, Beckert W, Lauke B, Ageorges C, Friedrich K (2000) Single fibre transverse debonding: stress analysis of the Broutman test. Composites A 31:661-670

37. Huguet S, Godin N, Gaertner R, Salmon L, Villard D (2002) Use of acoustic emission to identify damage modes in glass fibre reinforced polyester. Compos Sci Technol 62:1433-1444

38. Sause MGR, Gribov A, Unwin AR, Horn S (2012) Pattern recognition approach to identify natural clusters of acoustic emission signals. Pattern Recognit Lett 33:17-23

39. Turon A, Camanho PP, Costa J, Renart J (2010) Accurate simulation of delamination growth under mixed-mode loading using. Compos Struct 92:1857-1864

40. Daneshjoo Z, Shokrieh MM, Fakoor M, Alderliesten RC (2018) A new mixed mode I/II failure criterion for laminated composites considering fracture process zone. Theor Appl Fract Mech 98:48-58

41. Goutianos S (2017) Derivation of path independent coupled mix mode cohesive laws from fracture resistance curves. Appl Compos Mater 24:983-997

42. Serrano E, Gustafsson PJ (1999) Influence of bondline brittleness and defects on the strength of timber finger-joints. Int J Adhesion Adhesives 19:9-17

Publisher's Note Springer Nature remains neutral with regard to jurisdictional claims in published maps and institutional affiliations. 